\title{
Correction to: Number-needed-to-treat analysis of clinical progression in patients with metastatic castration-resistant prostate cancer in the STRIVE and TERRAIN trials
}

Neil M Schultz ${ }^{1 *}$, Neal D Shore ${ }^{2}$, Simon Chowdhury ${ }^{3}$, Laurence H Klotz ${ }^{4}$, Raoul S Concepcion ${ }^{5}$, David F Penson ${ }^{6}$, Lawrence I Karsh ${ }^{7}$, Hongbo Yang ${ }^{8}$, Bruce A Brown ${ }^{1}$, Arie Barlev ${ }^{9,10}$ and Scott C Flanders ${ }^{1}$

\section{Correction to Schultz et al. BMC Urology (2018)}

\section{8:77 DOI: 10.1186/s12894-018-0387-7}

It has been highlighted that in the original article [1] there was a typesetting mistake in the Results - NNT in Strive section. This Correction article states the incorrect and correct sentence.

Incorrect:

The NNT for rPFS at 2 year was 2.6 (upper, lower limits: $1.9,4.0)$ and at 2 years was $3.0(1.9,7.2)$ when comparing enzalutamide and bicalutamide.

Correct:

The NNT for rPFS at $\mathbf{1}$ year was 2.6 (upper, lower limits: $1.9,4.0)$ and at 2 years was $3.0(1.9,7.2)$ when comparing enzalutamide and bicalutamide.

\footnotetext{
Author details

${ }^{1}$ Astellas Pharma, Inc., 1 Astellas Way, Northbrook, IL 60062, USA. ${ }^{2}$ Carolina Urologic Research Center, Myrtle Beach, SC, USA. "3Guy's, King's, and St. Thomas' Hospitals, London, UK. ${ }^{4}$ Sunnybrook Health Sciences Centre, University of Toronto, Toronto, ON, Canada. ${ }^{5}$ Urology Associates, P.C, Nashville, TN, USA. ${ }^{6}$ Vanderbilt University Medical Center, Nashville, TN, USA. ${ }^{7}$ The Urology Center of Colorado, Denver, CO, USA. ${ }^{8}$ Analysis Group, Inc., Boston, MA, USA. " Medivation, Inc., San Francisco, CA, USA. ${ }^{10}$ Pfizer, Inc., New York, NY, USA.
}

Received: 21 September 2018 Accepted: 21 September 2018 Published online: 01 October 2018

\section{Reference}

1. Schultz NM, et al. Number-needed-to-treat analysis of clinical progression in patients with metastatic castration-resistant prostate cancer in the STRIVE and TERRAIN trials. BMC Urol. 2018;18:77.

\footnotetext{
* Correspondence: neil.schultz@astellas.com

${ }^{1}$ Astellas Pharma, Inc., 1 Astellas Way, Northbrook, IL 60062, USA

Full list of author information is available at the end of the article
}

(c) The Author(s). 2018 Open Access This article is distributed under the terms of the Creative Commons Attribution 4.0 International License (http://creativecommons.org/licenses/by/4.0/), which permits unrestricted use, distribution, and reproduction in any medium, provided you give appropriate credit to the original author(s) and the source, provide a link to the Creative Commons license, and indicate if changes were made. The Creative Commons Public Domain Dedication waiver (http://creativecommons.org/publicdomain/zero/1.0/) applies to the data made available in this article, unless otherwise stated. 